\title{
Thermolytic Degradation of Synthetic Cannabinoids: Chemical Exposures and Pharmacological Consequences
}

\author{
Brian F. Thomas, Timothy W. Lefever, Ricardo A. Cortes, Megan Grabenauer, \\ Alexander L. Kovach, Anderson O. Cox, ${ }^{1}$ Purvi R. Patel, Gerald T. Pollard, \\ Julie A. Marusich, Richard C. Kevin, Thomas F. Gamage, and Jenny L. Wiley \\ RTI International, Research Triangle Park, North Carolina (B.F.T., T.W.L., R.A.C., M.G., A.L.K., A.O.C, P.R.P, J.A.M, T.F.G, J.L.W.); \\ Howard Associates, LLC, Research Triangle Park, North Carolina (G.T.P.); and School of Psychology, The University of \\ Sydney, NSW, Australia (R.C.K.)
}

Received November 1, 2016; accepted January 12, 2017

\begin{abstract}
Synthetic cannabinoids are manufactured clandestinely with little quality control and are distributed as herbal "spice" for smoking or as bulk compound for mixing with a solvent and inhalation via electronic vaporizers. Intoxication with synthetic cannabinoids has been associated with seizure, excited delirium, coma, kidney damage, and other disorders. The chemical alterations produced by heating these structurally novel compounds for consumption are largely unknown. Here, we show that heating synthetic cannabinoids containing tetramethylcyclopropylring substituents produced thermal degradants with pharmacological activity that varied considerably from their parent compounds. Moreover, these degradants were formed under conditions simulating smoking. Some products of combustion retained high affinity at the cannabinoid $1\left(\mathrm{CB}_{1}\right)$ and $\mathrm{CB}_{2}$
\end{abstract}

receptors, were more efficacious than (-)-cis-3-[2-hydroxy-4(1,1-dimethylheptyl)phenyl]-trans-4-(3-hydroxypropyl)cyclohexanol (CP55,940) in stimulating $\mathrm{CB}_{1}$ receptor-mediated guanosine $5^{\prime}-\mathrm{O}$ (3-thiotriphosphate) (GTP $\gamma \mathrm{S}$ ) binding, and were potent in producing $\Delta^{9}$-tetrahydrocannabinol-like effects in laboratory animals, whereas other compounds had low affinity and efficacy and were devoid of cannabimimetic activity. Degradants that retained affinity and efficacy also substituted in drug discrimination tests for the prototypical synthetic cannabinoid 1-pentyl-3-(1-naphthoyl)indole (JWH-018), and are likely to produce psychotropic effects in humans. Hence, it is important to take into consideration the actual chemical exposures that occur during use of synthetic cannabinoid formulations to better comprehend the relationships between dose and effect.

\section{Introduction}

A variety of synthetic cannabinoids are being synthesized, distributed, and used as designer drugs to produce marijuanalike intoxication while evading drug detection by urinalysis

The research described in this manuscript was supported by the National Institutes of Health National Institute on Drug Abuse [Grants R01DA-040460 and R01DA-003672] and the National Institute of Justice, Office of Justice Programs, U.S. Department of Justice [Contract 2012-R2-CX-K001]. None of the funding agencies had any other role in study design; in the collection, analysis, and interpretation of data; in the writing of the report; or in the decision to submit the article for publication. The opinions, findings, and conclusions or recommendations expressed in this publication are those of the authors and do not necessarily reflect those of the Department of Justice or the National Institutes of Health.

${ }^{1}$ Current affiliation: Proteomics and Metabolomics Shared Resource, Comprehensive Cancer Center, Wake Forest School of Medicine, Winston-Salem, North Carolina. dx.doi.org/10.1124/jpet.116.238717. and its associated legal consequences (Auwarter et al., 2009; European Monitoring Centre for Drugs and Drug Addiction, 2010, 2015). These novel chemicals are typically formulated into an herbal product of questionable composition for combustion and inhalation administration. More recently, synthetic cannabinoids have also been encountered in liquid solutions for use in aerosol delivery devices (i.e., e-cigarette-like "vaporizers"). Unfortunately, data on the chemicals in the final products are scant, as is systematic study of their pharmacological and toxicological effects (Adamowicz et al., 2013; Grigoryev et al., 2013; Kavanagh et al., 2013; Bell and Nida, 2015).

Illicit manufacturers may have little knowledge, experience, or expertise in medicinal chemistry, and quality control often appears lacking. The chemical substituents used in the synthesis of new analogs appear relatively haphazard, failing

ABBREVIATIONS: A-834735, [1-[(tetrahydro-2H-pyran-4-yl)methyl]-1H-indol-3-yl](2,2,3,3-tetramethylcyclopropyl)-methanone; AM2201, [1-(5-fluoropentyl)-1H-indol-3-yl]-1-naphthalenyl-methanone; BSA, bovine serum albumin; CB, cannabinoid; CP55,940, (-)-cis-3-[2-hydroxy-4-(1,1dimethylheptyl)phenyl]-trans-4-(3-hydroxypropyl)cyclohexanol; GTP $\gamma\left[{ }^{35} \mathrm{~S}\right], 5^{\prime}-\mathrm{O}-\left(3-{ }^{35} \mathrm{~S}\right]$ thio)triphosphate; hCB, human cannabinoid receptor; JWH-018, 1-pentyl-3-(1-naphthoyl)indole; JWH-022, 1-naphthalenyl[1-(4-penten-1-yl)-1H-indol-3-yl]-methanone; JWH-073, (1-butyl-1Hindol-3-yl)-1-naphthalenyl-methanone; MN-18, N-1-naphthalenyl-1-pentyl-1H-indazole-3-carboxamide; MPTP, 1-methyl-4-phenyl-1,2,3,6tetrahydropyridine; NNEI, N-1-naphthalenyl-1-pentyl-1H-indole-3-carboxamide; 8-OH-quinoline, 8-hydroxyquinoline; PB-22, 1-pentyl-8-quinolinyl ester-1H-indole-3-carboxylic acid; SR144528, 5-(4-chloro-3-methylphenyl)-1-[(4-methylphenyl)methyl]- $N$-[(1S,2S,4R)-1,3,3-trimethylbicyclo[2.2.1]hept2-yl]-1H-pyrazole-3-carboxamide; THC, $\Delta^{9}$-tetrahydrocannabinol; UR-144, (1-pentyl-1H-indol-3-yl)(2,2,3,3-tetramethylcyclopropyl)-methanone; WIN55212-2, [(3R)-2,3-dihydro-5-methyl-3-(4-morpholinylmethyl)pyrrolo[1,2,3-de]-1,4-benzoxazin-6-yl]-1-naphthalenyl-methanone, monomethanesulfonate; XLR-11, (1-(5-fluoropentyl)-1H-indol-3-yl)(2,2,3,3-tetramethylcyclopropyl)methanone. 
to take into consideration chemical or metabolic stability, or other critical aspects involved in proper pharmaceutical chemistry. Moreover, the bulk chemicals or formulations are often exposed to variable levels of temperature, humidity, light, and other factors that can cause formation of degradation products over time. For instance, combustion in the presence of plant material, fillers, and adulterants, or vaporization in the presence of solvents, can produce degradants that may profoundly influence what the user actually self-administers. Consequently, the product may contain ingredients, degradants, and impurities with unexpected pharmacological effects.

Between January and May of 2015, U.S. poison centers in 48 states reported receiving 3572 calls related to synthetic cannabinoid use, a $229 \%$ increase from the 1085 calls received during the same January through May period in 2014. The 2015 figures included a spike of 1501 calls in April and 15 reported deaths, and inhalation use was involved in over $80 \%$ of these incidents (Law et al., 2015). Analogous to the case of the "frozen addicts" resulting from inadvertent exposure to (1-methyl-4-phenyl-1,2,3,6-tetrahydropyridine) MPTP (Langston et al., 1983), exposure to impurities or degradants in synthetic cannabinoid preparations is suspected to be responsible for a series of acute kidney injuries (Thornton et al., 2013). A wide variety of synthetic cannabinoids, including (1-(5-fluoropentyl)1H-indol-3-yl)(2,2,3,3-tetramethylcyclopropyl)methanone (XLR-11), (1-pentyl-1H-indol-3-yl)(2,2,3,3-tetramethylcyclopropyl)-methanone (UR-144), ADB-PINACA, AB-PINACA, AB-FUBINACA, and AB-CHMINACA, have been associated with adverse effects, including death (Lapoint et al., 2011; Hoyte et al., 2012; Thomas et al., 2012; Hermanns-Clausen et al., 2013; Thornton et al., 2013; Winstock and Barratt, 2013; Behonick et al., 2014; Monte et al., 2014; Tse et al., 2014; Koller et al., 2015; Law et al., 2015; Schwartz et al., 2015), and have been added to the list of Drug Enforcement Administration Schedule I controlled substances (Federal Register, 2013, 2014, 2015a,b).

In the United States, over 20 indole-containing synthetic cannabinoids have been added to Schedule I. In response to these actions, the chemical diversity of this class of compounds continues to increase and further deviate from the chemical scaffolds with known cannabinoid receptor activity (for example, see Wiley et al., 2015). For example, UR-144, XLR-11, and [1-[(tetrahydro-2H-pyran-4-yl)methyl]-1H-indol-3-yl] $(2,2,3,3$ tetramethylcyclopropyl)-methanone (A-834735) contain a ketone-linked tetramethylcyclopropyl ring substituent which replaces the naphthalene ring system present in the prototypical analog, 1-pentyl-3-(1-naphthoyl)indole (JWH-018). The tetramethylcyclopropyl ring system in these analogs is sterically strained and prone to ring opening (i.e., degradation) and thermolysis (Roberts and Landolt, 1965; Creary et al., 1977). 1-Pentyl-8-quinolinyl ester-1H-indole-3-carboxylic acid (PB-22), for comparison, has an ester-linked quinolone ring system that has both thermolytic and metabolic lability. Because of the variation in chemical structure, volatility, and stability, what individuals are actually exposed to during use and the pharmacological consequences remain to be determined. Thus, our objective was to identify the thermolysis products of these synthetic cannabinoids formed during heating under aerobic conditions of use, and determine their pharmacological effects in laboratory animals. These four parent compounds were chosen for analysis because they show thermolytic lability. In addition, each of the compounds has been specifically banned by the U.S. Drug Enforcement Administration
(Federal Register, 2015a, 2016) and/or has been mentioned by users in experiential forums (e.g., www.drugs-forum.com).

\section{Materials and Methods}

\section{Drugs and Chemicals}

JWH-018 and $\Delta^{9}$-tetrahydrocannabinol (THC) were obtained from the National Institute on Drug Abuse (Bethesda, MD) through the National Institute on Drug Abuse Drug Supply Program. XLR-11, UR-144, A-834735, and PB-22, as well as the ring-open degradants of XLR-11 (1-[1-(5-fluoropentyl)-1H-indol-3-yl]-3,3,4-trimethyl-4-penten-1-one), UR-144 (3,3,4-trimethyl-1-(1-pentyl-1H-indol-3-yl)pent-4-en-1-one), and A-834735 (3,3,4-trimethyl-1-(1-((tetrahydro-2H-pyran-4-yl)methyl)$1 \mathrm{H}$-indol-3-yl)pent-4-en-1-one) and the PB-22 3-carboxyindole metabolite (1-pentyl-1H-indole-3-carboxylic acid) were obtained from Cayman Chemical (Ann Arbor, MI). N-pentylindole and 8-hydroxyquinoline (8-OH-quinoline) were obtained from Toronto Research Chemicals (North York, ON, Canada). For the in vivo tests, the vehicle for all compounds was 7.8\% Polysorbate 80 N.F. (VWR, Marietta, GA) and $92.2 \%$ sterile saline USP (Butler Schein, Dublin, $\mathrm{OH})$. All compounds were injected at a volume of $10 \mathrm{ml} / \mathrm{kg}$.

Guanosine 5' diphosphate, bovine serum albumin, ammonium acetate, and formic acid were purchased from Sigma Chemical Company (St. Louis, MO). Guanosine 5'-O-(3-thiotriphosphate) $(\mathrm{GTP} \gamma \mathrm{S})$ was purchased from Roche Diagnostics (Indianapolis, IN). $5^{\prime}-O-\left(3-\left[{ }^{35} \mathrm{~S}\right]\right.$-thiotriphosphate $\left(\mathrm{GTP} \gamma\left[{ }^{35} \mathrm{~S}\right] ; 1150-1300 \mathrm{Ci} / \mathrm{mmol}\right)$ and scintillation fluid (MicroScint 20) were obtained from Perkin Elmer Life Sciences (Boston, MA). High-performance liquid chromatography grade acetonitrile and water were purchased from Fisher Scientific (Fairlawn, NJ). Reference standards and metabolite reference standards for all compounds were obtained from Cayman Chemical.

\section{Animals}

The tetrad battery and drug discrimination experiments used adult, drug-naïve male ICR mice (31-34 g; Harlan, Frederick, MD) and male C57/Bl6J mice (20-25 g; Jackson Laboratories, Bar Harbor, $\mathrm{ME}$ ), respectively. All mice were housed singly in polycarbonate cages in a temperature-controlled $\left(20-22^{\circ} \mathrm{C}\right)$ environment with a 12 -hour light-dark cycle (lights on at 6 a.m.) with ad libitum access to water. ICR mice received unlimited access to standard rodent chow and were tested no more than twice in the tetrad battery. Mice in the drug discrimination experiments were maintained at $85-90 \%$ of freefeeding body weights by restricting daily ration of standard rodent chow. The in vivo studies were carried out in accordance with federal regulatory guidelines and were approved by our Institutional Animal Care and Use Committee.

\section{Apparatus}

For the tetrad test battery in mice, spontaneous activity was measured in Plexiglas locomotor activity chambers $(47 \times 25.5 \times$ $22 \mathrm{~cm}$, Arkema, Colombes, France). Beam breaks ( $4 \times 8$ beam array) were recorded by San Diego Instruments Photobeam Activity System software (San Diego, CA) on a computer located in the experimental room. A standard tail-flick device for rodents (Stoelting, Dale, IL) was used to assess antinociception. A digital thermometer (Physitemp Instruments, Inc., Clifton, NJ) was used to measure rectal temperature. The ring immobility device consisted of an elevated metal ring (diameter $=5.5 \mathrm{~cm}$, height $=28 \mathrm{~cm}$ ) attached to a metal stand.

Mouse operant chambers (Coulbourn Instruments, Whitehall, PA), housed within light- and sound-attenuating cubicles, were used in drug discrimination. Each chamber contained two nose-poke apertures, with stimulus lights located over each aperture, and a house light. A food dispenser delivered 20-mg food pellets (Bioserv Inc., Frenchtown, NJ) into a food cup (with a light) centered between the two apertures. Experimental events were controlled by a 
computer-based system (Graphic State Software, version 3.03; Coulbourn Instruments).

\section{Experimental Procedures}

Pyrolysis. A 5250T thermolysis/pyrolysis probe (CDS Analytical Inc., Oxford, PA) equipped with an autosampler turret was coupled to an Agilent 7000 triple quadrupole gas chromatography/mass spectrometry system (Agilent Technologies, Santa Clara, CA) for separation and identification of volatile chemicals liberated upon heating. Aliquots of XLR-11, UR-144, A-834735, and PB-22 were dissolved in acetonitrile separately. Five-microgram aliquots were then transferred into individual quartz capillary tubes (in triplicate), evaporated to dryness, and placed in the thermolysis/pyrolysis system's autosampler turret. The system transferred individual samples to the thermolysis/pyrolysis probe equilibrated at $50^{\circ} \mathrm{C}$, which was then rapidly heated to $800^{\circ} \mathrm{C}\left(20^{\circ} \mathrm{C} / \mathrm{s}\right)$ under an ambient (zero grade) airflow (a condition that approximates the burning end of a cigarette) and passed through a charcoal trap/desorption tube held at $50^{\circ} \mathrm{C}$. The probe was held at $800^{\circ} \mathrm{C}$ for 20 seconds, and then airflow was switched to helium for 1.18 minutes while the thermolysis/pyrolysis probe was returned to $50^{\circ} \mathrm{C}$ and equilibrated. Subsequently, the charcoal desorption tube was rapidly heated to $300^{\circ} \mathrm{C}$ while the helium flow was diverted to the inlet of the gas chromatograph for separation and analysis of thermolysis products by full-scan mass spectrometry $(\mathrm{m} / \mathrm{z} 50-550)$ using electron ionization $(70 \mathrm{eV})$. The inlet of the gas chromatograph was set to $300^{\circ} \mathrm{C}$. The gas chromatograph capillary column (DB-1, $30 \mathrm{~m} \times 250 \mu \mathrm{m} \times 0.25 \mu \mathrm{m}$, Agilent Technologies, Santa Clara, CA) was maintained at $40^{\circ} \mathrm{C}$ during the transfer, increased (1-minute hold) at $10^{\circ} \mathrm{C} / \mathrm{min}$ to $300^{\circ} \mathrm{C}(9$-minute hold), and then increased at $15^{\circ} \mathrm{C} / \mathrm{min}$ to $325^{\circ} \mathrm{C}$ (5-minute hold). The helium carrier gas flow rate was $1 \mathrm{ml} / \mathrm{min}$. During the gas chromatography temperature increase, the mass spectrometer acquired full-scan data with unit resolution.

Radioligand Binding Competitive Displacement Assay. Transfected cell membrane preparations with human $\mathrm{CB}_{1}\left(\mathrm{hCB}_{1}\right)$ and human $\mathrm{CB}_{2}\left(\mathrm{hCB}_{2}\right)$ receptors (PerkinElmer) isolated from a HEK-293 expression system were used for cannabinoid binding assays, as previously described (Zhang et al., 2010). In brief, binding was initiated with the addition of $40 \mathrm{fmol}$ of cell membrane proteins to polypropylene assay tubes containing $0.62 \mathrm{nM}\left[{ }^{3} \mathrm{H}\right] \mathrm{CP} 55,940$ [(-)-cis-3-[2-hydroxy-4-(1,1dimethylheptyl)phenyl]-trans-4-(3-hydroxypropyl)cyclohexanol; ca. $130 \mathrm{Ci} / \mathrm{mmol}$, a test compound (for displacement studies), and a sufficient quantity of buffer A [50 mM Tris. $\mathrm{HCl}, 1 \mathrm{mM}$ EDTA, $3 \mathrm{mM}$ $\mathrm{MgCl}_{2}, 5 \mathrm{mg} / \mathrm{ml}$ bovine serum albumin (BSA), $\mathrm{pH}$ 7.4] to bring the total incubation volume to $0.5 \mathrm{ml}$. Nonspecific binding was determined by the inclusion of $10 \mu \mathrm{M}$ unlabeled CP55,940. All cannabinoid agonists were prepared from a $10 \mathrm{mM}$ ethanol stock by suspension in buffer A. Following incubation at $30^{\circ} \mathrm{C}$ for 1 hour, binding was terminated by vacuum filtration through GF/C glass fiber filter plates (PerkinElmer), pretreated in $0.1 \%(\mathrm{w} / \mathrm{v})$ polyethylenimine for at least 1 hour, in a 96-well sampling manifold (Brandel, Gaithersburg, $\mathrm{MD})$. Reaction vessels were washed three times with $\sim 2 \mathrm{ml}$ of ice-cold buffer B ( $50 \mathrm{mM}$ Tris.HCl, $1 \mathrm{mg} / \mathrm{ml}$ BSA). The filter plates were air dried and sealed on the bottom. Liquid scintillate was added to the wells, and the top was sealed. Liquid scintillation spectrometry was used to measure radioactivity after incubating the plates in cocktail for at least 30 minutes. Assays were done in duplicate, and results represent combined data from independent displacement curves.

Agonist-Stimulated GTP $\gamma\left[{ }^{\mathbf{3 5}} \mathbf{S}\right]$ Binding. G-protein-coupled signal transduction $\left(\mathrm{GTP} \gamma\left[{ }^{35} \mathrm{~S}\right]\right)$ assays of test compounds were conducted in an incubation mixture consisting of a test compound $(0.25 \mathrm{nM}$ to $20 \mu \mathrm{M}), \mathrm{GDP}(20 \mu \mathrm{M}), \mathrm{GTP} \gamma\left[{ }^{35} \mathrm{~S}\right](100 \mathrm{pM})$, and the $\mathrm{hCB}_{1}$ and $\mathrm{hCB}_{2}$ membrane preparations described earlier $(40 \mathrm{fmol})$ in a total volume of $0.45 \mathrm{ml}$ of assay buffer [50 mM Tris- $\mathrm{HCl}(\mathrm{pH} 7.4), 1 \mathrm{mM}$ EDTA, $100 \mathrm{mM} \mathrm{NaCl}, 3 \mathrm{mM} \mathrm{MgCl}_{2}$, and $0.5 \%$ (w/v) BSA]. Nonspecific binding was determined in the presence of $100 \mu \mathrm{M}$ unlabeled GTP $\gamma \mathrm{S}$, and basal binding was determined in the absence of drug. Duplicate samples were incubated for 1 hour at $30^{\circ} \mathrm{C}$, and the bound complex was filtered from the reaction mixture as previously described and counted in a liquid scintillation counter.

Mouse Tetrad. Each mouse was tested in a battery of four sequential tests, in which cannabinoid agonists produce a profile of in vivo effects (Martin et al., 1991): suppression of locomotor activity, decreased rectal temperature, antinociception, and catalepsy. Rectal temperature and baseline latency in the tail-flick test were measured before injection. Subsequently, mice were injected i.p. with vehicle or drug 30 minutes before being placed into individual activity chambers for a 10-minute session, during which the number of photocell beam breaks was recorded. Immediately upon removal from the chambers, tail-flick latency and rectal temperature were measured again. In the tail-flick procedure, the mouse's tail was placed under an intense light (radiant heat), and the latency (seconds) to remove it was recorded. To minimize tail damage, a maximal latency (10 seconds) was used. The ring immobility test occurred at 50 minutes postinjection. The amount of time the animals remained motionless on an elevated ring apparatus during a 5-minute period was recorded. If a mouse fell off the ring during the catalepsy test, it was immediately placed back on, and timing was continued for up to nine falls. After the 10th fall, the test was terminated for the mouse. Six male ICR mice were tested with each dose (and vehicle) of each compound.

Drug Discrimination. Prior to the beginning of this study, one group of adult male mice $(n=7)$ was trained to discriminate JWH-018 in a lever-press procedure in standard operant chambers. Dose-effect curve determinations were completed with JWH-018, (1-butyl-1H-indol3-yl)-1-naphthalenyl-methanone (JWH-073), and THC, and antagonist tests were conducted with $0.3 \mathrm{mg} / \mathrm{kg}$ JWH-018 and the $\mathrm{CB}_{1}$ and $\mathrm{CB}_{2}$ antagonists rimonabant and 5-(4-chloro-3-methylphenyl)-1-[(4-methylphenyl)methyl]$N$-[(1S,2S,4R)-1,3,3-trimethylbicyclo[2.2.1] hept-2-yl]-1H-pyrazole3-carboxamide (SR144528), respectively (Wiley et al., 2016). Subsequently, the response requirement was changed from lever presses to nose pokes. This change was necessitated by the transition of all of the laboratory's mouse operant equipment to nose-poke apertures and was not specifically related to this study. With the exception of the actual response (nose poke versus lever press), all other procedural details remained the same and are described. After acquisition of the nose-poke response, substitution tests with ring-open degradants of UR-144, XLR-11, and A-834735 and the 3-carboxyindole metabolite of PB-22 were conducted, followed by redetermination of a doseeffect curve for JWH-018. Doses of all compounds were tested in ascending order. Prior to each dose-effect curve, mice were retested with vehicle and $0.3 \mathrm{mg} / \mathrm{kg}$ JWH-018 to confirm continued accuracy in the discrimination task.

In brief, mice were retrained to respond on one of two apertures following i.p. administration of $0.3 \mathrm{mg} / \mathrm{kg} \mathrm{JWH}-018$ and to respond on the other aperture after i.p. vehicle injection. A food pellet was delivered after 10 consecutive responses on the correct (injectionappropriate) aperture (i.e., fixed ratio 10). Responses on the incorrect aperture reset the ratio requirement on the correct aperture. The double alternation sequence of JWH-018 and vehicle injections (e.g., drug, drug, vehicle, vehicle) was maintained. Fifteen-minute test sessions occurred no more than twice weekly, with training sessions occurring on intervening weekdays. Procedures were similar to training, with the exception that 10 consecutive responses on either aperture delivered reinforcement. To be tested for substitution, mice had to meet the following three criteria on the preceding day and during the previous training session with the alternate training compound (training drug or vehicle): (1) the first completed fixed ratio 10 was on the correct aperture, $(2) \geq 80 \%$ of the total responding occurred on the correct aperture, and (3) response rate was $\geq 0.17$ responses/s.

Degradants ( $N$-pentylindole and 8-OH-quinoline) and the 3-carboxyindole metabolite of PB-22 were assessed in a second group of male mice $(n=6)$ trained to discriminate $5.6 \mathrm{mg} / \mathrm{kg}$ THC from vehicle. These mice were trained using methods and criteria described earlier for JWH-018 discrimination. Before testing with the PB-22 degradants and metabolite, substitution tests with a number of other 
synthetic cannabinoids had occurred. Data for these prior tests are not included in this study.

\section{Data Analysis}

Binding Data Analysis. Specific binding was calculated by subtracting nonspecific binding from total binding for each concentration of displacing ligand. For displacement studies, curve-fitting and $\mathrm{IC}_{50}$ calculations were done with GraphPad Prism (version 5; GraphPad Software, Inc., San Diego, CA), which fits the data to oneand two-site models and compares the two fits statistically. $\mathrm{K}_{\mathrm{i}}$ values were estimated from $\mathrm{IC}_{50}$ values using the Cheng-Prusoff equation.

Specific binding of GTP $\gamma\left[{ }^{35} \mathrm{~S}\right]$ was calculated by subtracting nonspecific binding from total binding. Net stimulated GTP $\gamma\left[{ }^{35} \mathrm{~S}\right]$ binding was defined as agonist-stimulated minus basal GTP $\gamma\left[{ }^{35} \mathrm{~S}\right]$ binding, and percentage stimulation was defined as (net stimulated/basal GTP $\gamma\left[{ }^{35} \mathrm{~S}\right]$ binding) $\times 100 \%$. Data were plotted as $\log$ (agonist) against response and analyzed with global nonlinear regression with a constrained "shared" basal value using GraphPad Prism 6.0.

Mouse Tetrad. Spontaneous activity was measured as the total number of photocell beam interruptions during the 10-minute session. For the purpose of potency calculation, it was expressed as percentage inhibition of activity of the vehicle group. Antinociception was expressed as the percentage maximum possible effect using a 10-second maximum test latency as follows: [(test-control) $/(10$-control $)] \times 100$. Rectal temperature values were expressed as the difference between control temperature (before injection) and temperature following drug administration $\left(\Delta^{\circ} \mathrm{C}\right)$. For catalepsy, the total amount of time (seconds) that the mouse remained motionless on the ring apparatus (except for breathing and whisker movement) was used as an indication of catalepsy-like behavior. This value was divided by 300 seconds and multiplied by 100 to obtain a percentage immobility. For compounds that produced one or more cannabinoid effects, $\mathrm{ED}_{50}$ was calculated separately using least-squares linear regression on the linear part of the dose-effect curve for each measure in the mouse tetrad, plotted against $\log 10$ transformation of the dose. $\mathrm{ED}_{50}$ was defined as the dose at which the half-maximal effect occurred. Maximal cannabinoid effect in each procedure was estimated as follows: $100 \%$ inhibition of spontaneous activity, $100 \%$ maximum possible effect in the tail flick, $-6^{\circ} \mathrm{C}$ change in rectal temperature, and $60 \%$ ring immobility.

Drug Discrimination. For each session, percentage of responses on the drug-associated manipulandum and response rate (responses/s) were calculated. For drugs that substituted for JWH-018 or THC, $\mathrm{ED}_{50}$ values were calculated on the linear part of the drug aperture selection dose-response curve for each drug using leastsquares linear regression analysis, followed by calculation of $95 \%$ confidence intervals. Since mice that responded less than 10 times during a test session did not respond on either aperture a sufficient number of times to earn a reinforcer, their data were excluded from analysis of drug aperture selection, but their response-rate data were included. Response-rate data were analyzed using repeated-measures analysis of variance across dose. Significant analyses of variance were further analyzed with Tukey post hoc tests $(\alpha=0.05)$ to specify differences between means.

\section{Results}

Thermolysis Results. Figure 1 shows chromatograms obtained during the thermolysis of synthetic cannabinoids demonstrating that volatility and thermal stability varied widely, depending on chemical class and structural substituents. For example, the ketone-linked alkylindole JWH-018 showed high stability and volatility ( $>90 \%$ parent recovered) when rapidly heated to $800^{\circ} \mathrm{C}$, whereas the ester-linked alkylindole PB-22 showed thermolytic lability such that no parent was recovered. Specifically, PB-22 underwent complete
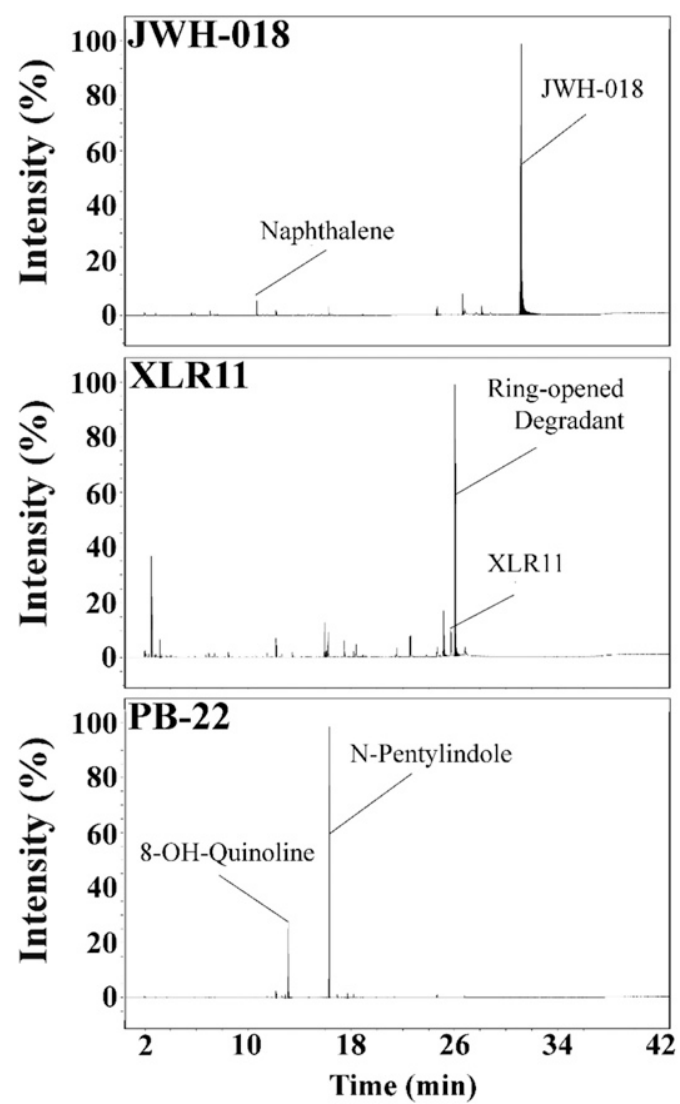
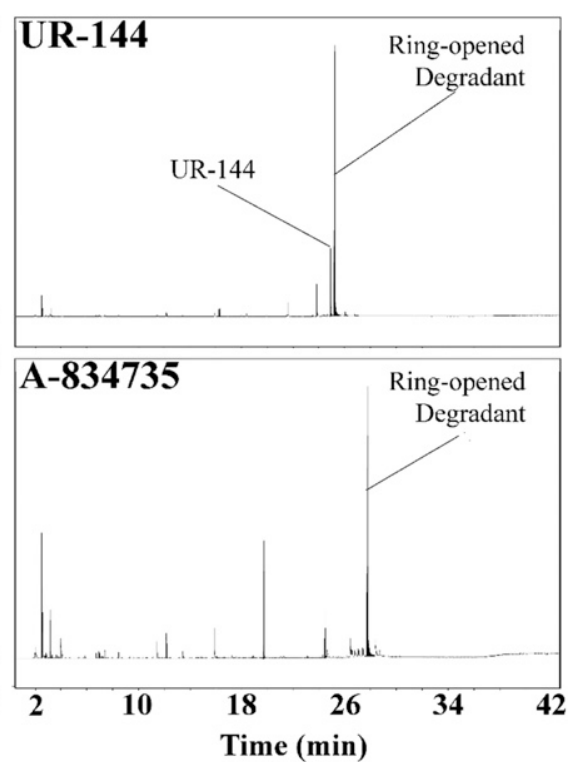

Fig. 1. Thermolysis of synthetic cannabinoids. Total ion chromatograms showing the results of aerobic thermolysis of JWH018, UR-144, XLR-11, A-834735, and PB-22 at $800^{\circ} \mathrm{C}$. Note the differing degrees of degradation due to differences in chemical structure. Each chromatogram is shown plotted as normalized intensity (percentage) on the $y$-axis and elution time (minutes) on the $x$-axis. 
thermolytic cleavage around the ester bonds to form the volatile degradants $\mathrm{N}$-pentylindole and 8 - $\mathrm{OH}$-quinoline. The compounds containing tetramethylcyclopropyl ring systems (e.g., XLR-11, UR-144, and A-834735) were susceptible to thermally induced ring-opening reactions that have previously been reported to occur during prolonged storage or heating (Creary et al., 1977; Adamowicz et al., 2013; Grigoryev et al., 2013). Figure 2 provides the structures of both the parent compounds and their thermolytic or metabolic degradants.
Cannabinoid Receptor Binding and AgonistStimulated GTP $\gamma\left[{ }^{\mathbf{3 5}} \mathbf{S}\right]$ Binding. Figures 3 and 4 illustrate the ability of the synthetic cannabinoid compounds to compete for $\left[{ }^{3} \mathrm{H}\right] \mathrm{CP} 55,940$ binding to cannabinoid receptors (affinity) and affect signal transduction as measured by GTP $\gamma\left[{ }^{35} \mathrm{~S}\right]$ binding (efficacy). The positive control, CP55,940, potently displaced $\left[{ }^{3} \mathrm{H}\right] \mathrm{CP} 55,940$ binding to $\mathrm{hCB}_{1}$ and $\mathrm{hCB}_{2}$ receptors with similar nanomolar affinity (Table 1 ). Compared with CP55,940, XLR-11, UR-144, and A-834735 had 20- to<smiles>CCCCCCC(C)(C)c1ccc(C2CCCC(O)C2)c(O)c1</smiles>

CP55,940<smiles>CCCCCn1cc(C(=O)c2cccc3ccccc23)c2ccccc21</smiles>

JWH-018<smiles>C=C(C)C(C)(C)CC(=O)c1cn(CC2CCOCC2)c2ccccc12</smiles>

A-834735 Degradant

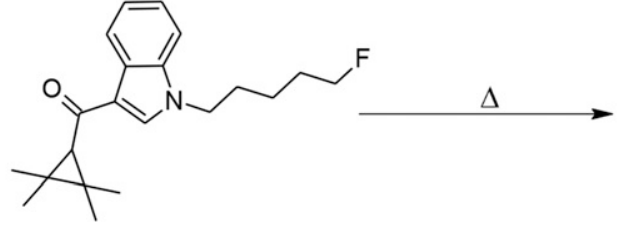

XLR11<smiles>CCCCCn1cc(C(=O)C2C(C)(C)C2(C)C)c2ccccc21</smiles>

UR-144

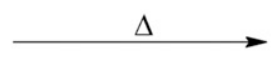<smiles>C=C(C)C(C)(C)CC(=O)c1cn(CCCCCF)c2ccccc12</smiles>

XLR11 Degradant<smiles>C=C(C)C(C)(C)CC(=O)c1cn(CCCCC)c2ccccc12</smiles>

UR-144 Degradant

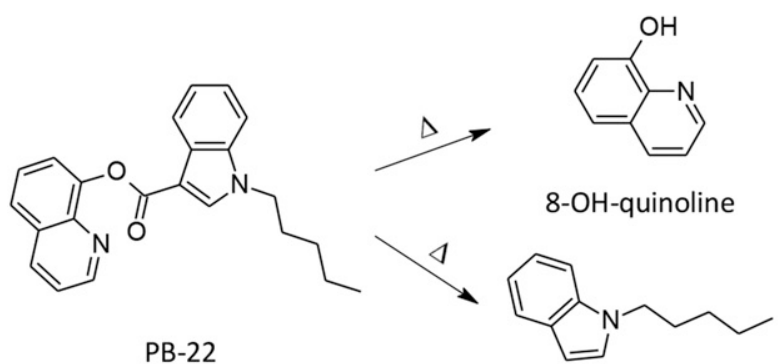

$\mathrm{N}$-pentylindole<smiles>CCCCCn1cc(C(=O)O)c2ccccc21</smiles>

1-pentyl-1H-indole-3-carboxylic acid

(PB-22-3-carboxyindole metabolite)

Fig. 2. Structures of synthetic cannabinoid analogs and their degradants or metabolites 

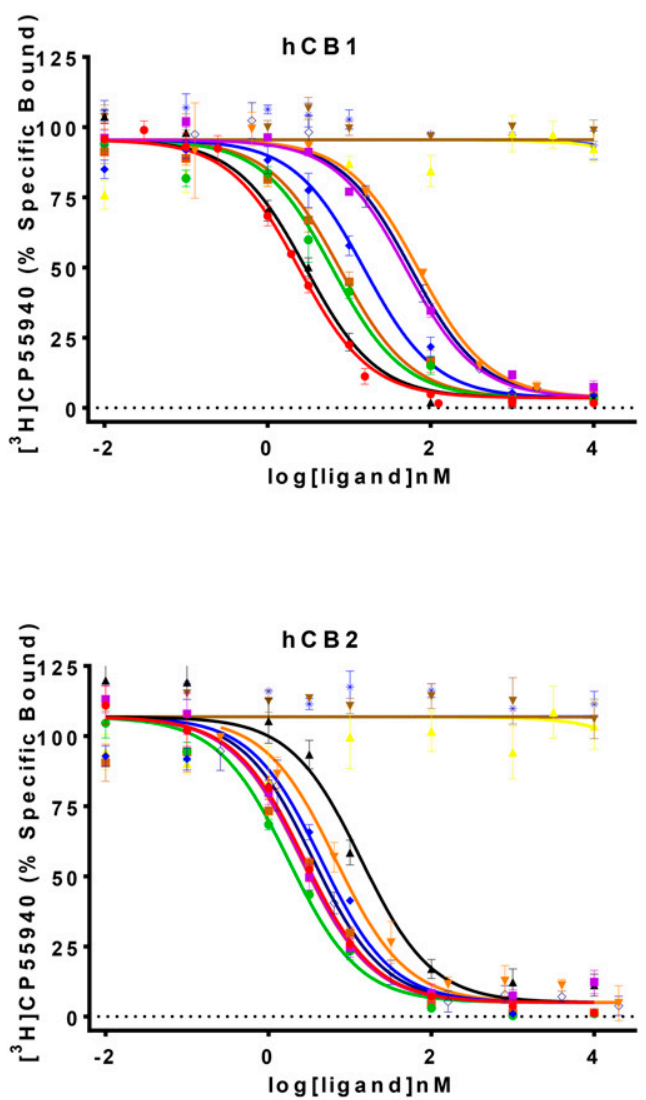

Fig. 3. Displacement of $\left[{ }^{3} \mathrm{H}\right] \mathrm{CP} 55,940$ by synthetic cannabinoid analogs in $\mathrm{hCB}_{1^{-}}$(top) and $\mathrm{hCB}_{2}$-transfected (bottom) cell lines. Each data point has error bars depicting the standard error of the mean, and each displacement curve represents the global nonlinear regression of the average data for each analog. 8-HQ, 8-hydroxyquinoline.

29-fold lower affinities at the $\mathrm{hCB}_{1}$ receptor while retaining higher affinities at the $\mathrm{hCB}_{2}$ receptor that were more similar to $\mathrm{CP} 55,940$ 's $\mathrm{hCB}_{2}$ receptor affinity. Compared with their parent compounds, the ring-open degradants of XLR-11, UR-144, and A-834735 possessed 4.6- to 8-fold higher affinities at the $\mathrm{hCB}_{1}$ receptor and 1.4- to 1.5 -fold higher affinities at the $\mathrm{hCB}_{2}$ receptor. The $\mathrm{hCB}_{1}$ receptor affinity of $\mathrm{PB}-22$ was comparable to that of $\mathrm{CP} 55,940$, whereas its $\mathrm{hCB}_{2}$ receptor affinity was $\sim 5$-fold lower. However, unlike the other parent compounds, its thermolytic degradants $(N$-pentylindole and 8-OH-quinoline) and the 3-carboxyindole metabolite of $\mathrm{PB}-22$ did not displace $\left[{ }^{3} \mathrm{H}\right] \mathrm{CP} 55,940$ binding to either $\mathrm{hCB}_{1}$ or $\mathrm{hCB}_{2}$ receptors at concentrations exceeding $1 \mu \mathrm{M}$.

As expected, CP55,940 was an equipotent agonist at both cannabinoid receptors (Fig. 4; Table 1), increasing GTP $\gamma\left[{ }^{35} \mathrm{~S}\right]$ specific binding by approximately 2 -fold over basal levels at the $\mathrm{hCB}_{1}$ receptor and approximately 1.6 -fold over basal levels at the $\mathrm{hCB}_{2}$ receptor. XLR-11, UR-144, and A-834735 ranged from approximately 6- to 76-fold less potent than CP55,940 at the $\mathrm{hCB}_{1}$ receptor and 1- to 31 -fold less potent at the $\mathrm{hCB}_{2}$ receptor. Whereas XLR-11 and UR-144 were similar to CP55,940 in efficacy for the $\mathrm{hCB}_{1}$ receptor, the efficacy of A-834735 was nearly twice that of CP55,940. Efficacies of all three parent tetramethylcyclopropyl compounds at the $\mathrm{hCB}_{2}$ receptor approximated that of CP55,940. The ring-open degradants of XLR-11, UR-144, and A-834735 were slightly more potent (1- to 12.3 -fold) at stimulating GTP $\gamma\left[{ }^{35} \mathrm{~S}\right]$ binding
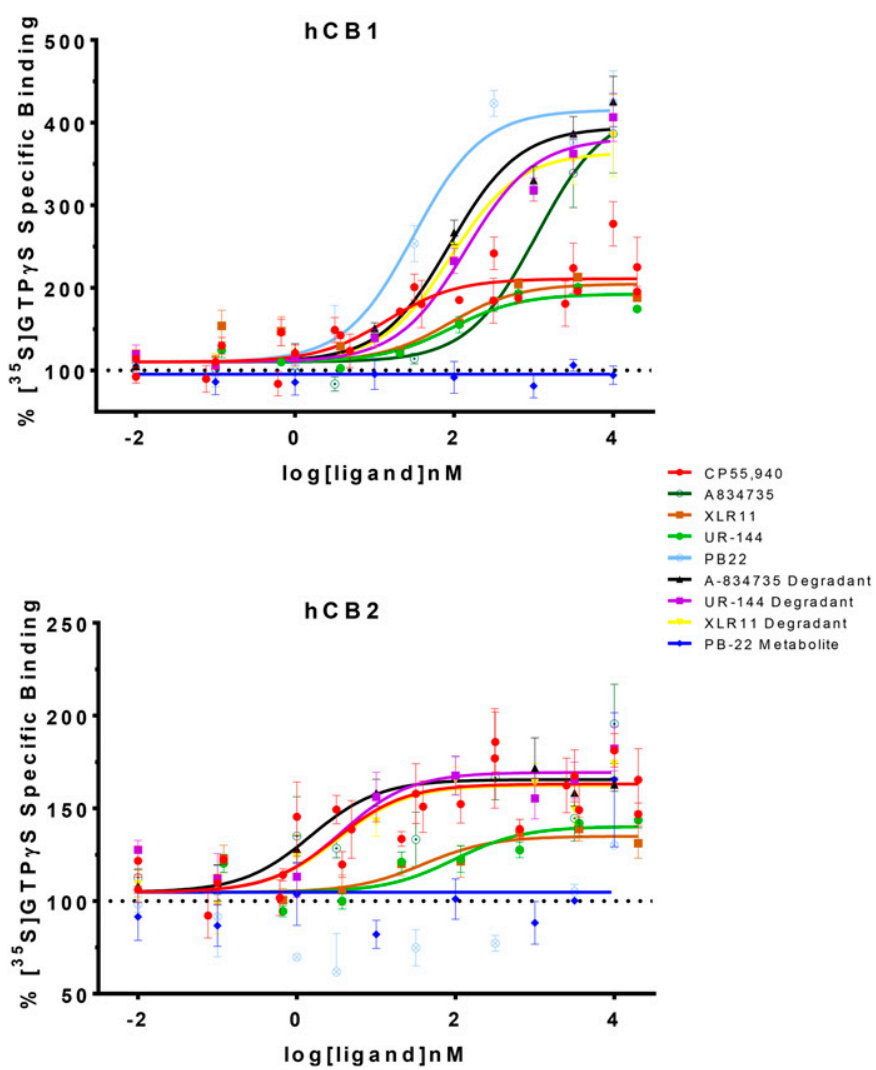

Fig. 4. Effect of synthetic cannabinoids on $\operatorname{GTP} \gamma\left[{ }^{35} \mathrm{~S}\right]$ binding in $\mathrm{hCB}_{1}$ and $\mathrm{hCB}_{2}$ receptor-transfected cell lines. Each data point has error bars depicting the standard error of the mean, and each concentration-effect curve represents the global nonlinear regression for at least two experimental repetitions.

at $\mathrm{hCB}_{1}$ receptors than their parent compounds and 2.2- to 26.7-fold more potent at the $\mathrm{hCB}_{2}$ receptor. Whereas efficacies of the ring-open degradants of XLR-11 and UR-144 were $\sim 1$ - to 2 -fold higher than their parent compounds at both cannabinoid receptors, efficacy of the ring-open degradant of A-834735 was equal to and slightly lower (1.1-fold) than its parent compound at the $\mathrm{hCB}_{2}$ and $\mathrm{hCB}_{1}$ receptors, respectively. PB-22 was more potent at stimulating GTP $\gamma\left[{ }^{35} \mathrm{~S}\right]$ binding at the $\mathrm{hCB}_{1}$ receptor than the tetramethylcyclopropyl compounds and their ring-open degradants, with high efficacy that was similar to A-834735 and its ring-open degradant. In contrast, PB-22 failed to stimulate GTP $\gamma\left[{ }^{35} \mathrm{~S}\right]$ binding at the $\mathrm{hCB}_{2}$ receptor at all but the highest concentration tested $(\sim 10 \mu \mathrm{M})$. Similarly, the 3-carboxyindole metabolite of PB-22 did not affect GTP $\gamma\left[{ }^{35} \mathrm{~S}\right]$ binding at any concentration, which is consistent with its lack of receptor affinity (Fig. 4; Table 1). Since the thermolytic degradants of PB-22 ( $N$-pentylindole and 8-OH-quinoline) also failed to displace $\left[{ }^{3} \mathrm{H}\right] \mathrm{CP} 55,940$ from the $\mathrm{hCB}_{1}$ or $\mathrm{hCB}_{2}$ receptor, they were not further assessed in the GTP $\gamma\left[{ }^{35} \mathrm{~S}\right]$ assay.

Mouse Tetrad Effects. Parent compounds (A-834735, XLR-11, UR-144, PB-22) and the ring-open degradants of A-834735, XLR-11, and UR-144 exhibited the complete profile of cannabinoid effects in the tetrad tests in mice, with each compound producing dose-dependent suppression of spontaneous activity, antinociception, hypothermia, and ring immobility (Table 2). In contrast, the degradants and 3 -carboxyindole metabolite of $\mathrm{PB}-22$ were inactive in one or 
TABLE 1

Binding affinity and potency and efficacy for stimulation of $\mathrm{GTP} \gamma\left[{ }^{35} \mathrm{~S}\right]$ binding at $\mathrm{hCB}_{1}$ and $\mathrm{hCB}_{2}$ receptors

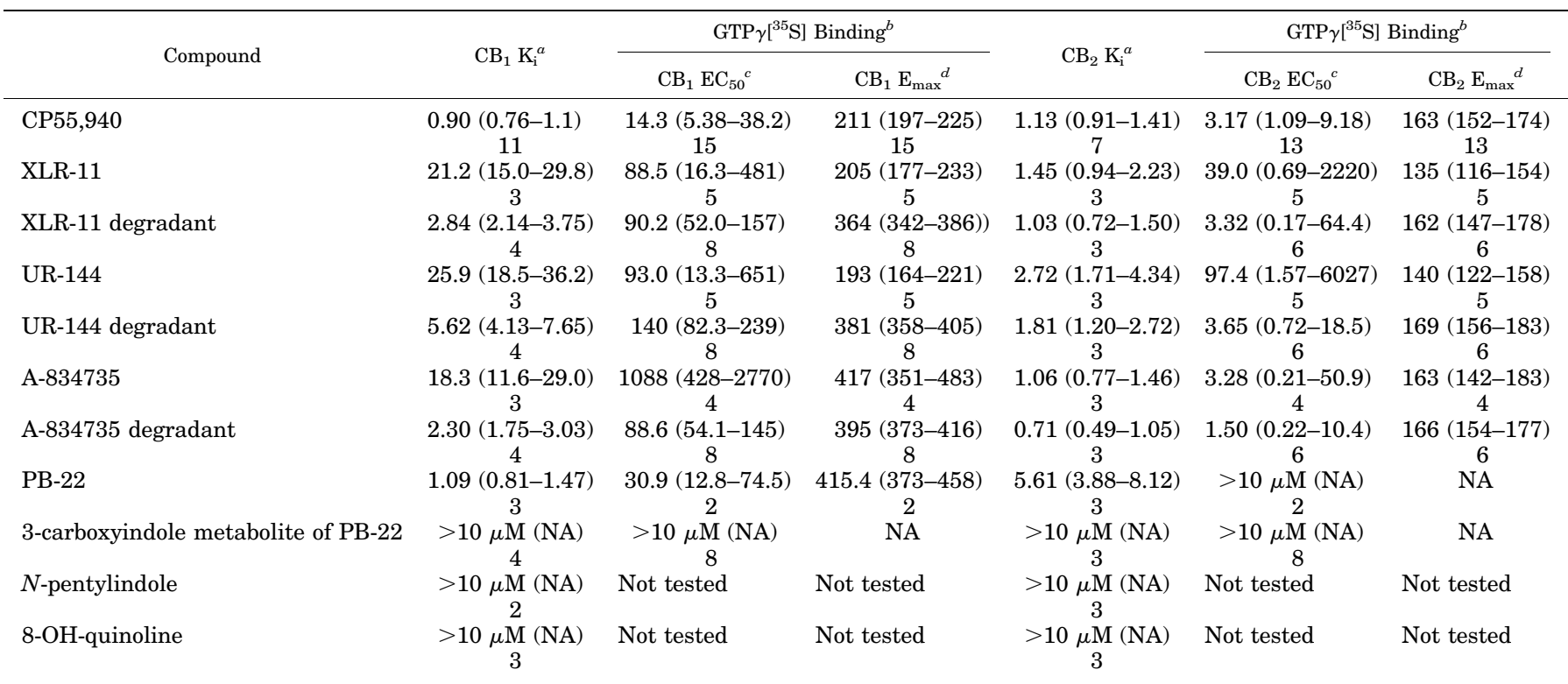

NA, not applicable.

${ }^{a}$ Values represent $\mathrm{K}_{\mathrm{i}}$ values ( \pm S.E.M.) in $\mathrm{nM}$ for $\left[{ }^{3} \mathrm{H}\right] \mathrm{CP} 55,940$ displacement at specified $\left(\mathrm{hCB}_{1}\right.$ or hCB $\mathrm{h}_{2}$ ) receptor.

${ }^{b}$ For each measure in all columns, $\mathrm{n}$ is shown below the SEM.

${ }^{c}$ Values represent $\mathrm{EC}_{50}$ values (95\% confidence interval) in $\mathrm{nM}$ for $\mathrm{GTP} \gamma\left[{ }^{35} \mathrm{~S}\right]$ binding at specified $\left(\mathrm{hCB}_{1}\right.$ or $\left.\mathrm{hCB}_{2}\right)$ receptor.

${ }^{d}$ Values represent percentage GTP $\gamma\left[{ }^{35} \mathrm{~S}\right]$-specific binding with basal set at the global percentage shared $(\sim 100 \%)$ determined at the specified $\left(\mathrm{hCB} \mathrm{B}_{1}\right.$ or hCB $\left.\mathrm{B}_{2}\right)$ receptor subtype.

more tetrad tests. For antinociception, hypothermia, and ring immobility, rank-order potencies for A-834735, XLR-11, and UR-144 were generally consistent with affinities of these parent compounds for the $\mathrm{CB}_{1}$ receptor (A-834735 > XLR-11 $\sim$ UR-144). Whereas the potencies of XLR-11 and UR-144 were similar to those obtained with THC (i.e., overlapping confidence limits for most measures), A-834735 was $\sim 2$ - to 26 -fold more potent than THC (Table 2). Opening the tetramethylcyclopropyl ring resulted in active compounds with substantially (2.4- to 59-fold) enhanced potency in all four assays (Table 2). In contrast, a probe dose of $30 \mathrm{mg} / \mathrm{kg}$ of $\mathrm{N}$-pentylindole or the 3 -carboxyindole metabolite of $\mathrm{PB}-22$ did not produce cannabimimetic effects in any of the assays, and 8-OH-quinoline produced a dose-responsive decrease in locomotor activity and rectal temperature, but did not produce antinociception or ring immobility (Table 2). Their parent compound PB-22 was more potent than any of the other parent or degradant compounds tested in all four assays (Table 2).

Drug Discrimination in Mice. Upon retraining in the nose-poke procedure, JWH-018 continued to engender dosedependent substitution for the $0.3-\mathrm{mg} / \mathrm{kg}$ training dose (Fig. 5 , top panel). It was previously shown that XLR-11 and UR-144 could fully substitute for THC in a THC discrimination procedure in mice, effects that were attenuated by rimonabant (Wiley et al., 2013). In this study, the degradants of UR-144, XLR-11, and A-834735 fully and dose dependently substituted

TABLE 2

Potencies in the tetrad tests

Values represent $\mathrm{ED}_{50}$ values $( \pm 95 \%$ confidence limits). Values in parentheses below "no effect" indicate highest dose tested. All compounds were administered i.p. $(\mathrm{n}=$ 6 mice/dose).

\begin{tabular}{|c|c|c|c|c|}
\hline Compound & \multicolumn{4}{|c|}{ Tetrad Test $\mathrm{ED}_{50}$ Values } \\
\hline & $\mu \mathrm{mol} / \mathrm{kg}$ & $\mu \mathrm{mol} / \mathrm{kg}$ & $\mu \mathrm{mol} / \mathrm{kg}$ & $\mu \mathrm{mol} / \mathrm{kg}$ \\
\hline XLR-11 & $41.12(23.82-71.02)$ & $70.99(19.03-\mathrm{nc})$ & $12.78(7.16-22.73)$ & $50.38(13.23-\mathrm{nc})$ \\
\hline XLR-11 degradant & $6.16(4.19-9.05)$ & $2.25(1.34-3.78)$ & $3.71(2.00-6.88)$ & $6.32(3.93-10.16)$ \\
\hline UR-144 & $75.79(23.11-\mathrm{nc})$ & $33.26(14.96-73.96)$ & $29.92(24.21-37.01)$ & $50.38(13.23-\mathrm{nc})$ \\
\hline UR-144 degradant & $1.28(0.77-2.12)$ & $2.57(0.92-7.19)$ & $8.01(2.41-26.62)$ & $4.87(3.66-6.49)$ \\
\hline PB-22 & $1.73(1.03-2.90)$ & $1.04(0.45-2.41)$ & $0.28(0.23-0.35)$ & $0.66(0.42-1.03)$ \\
\hline 3-Carboxyindole metabolite of PB- 22 and $N$-pentylindole & \multicolumn{4}{|c|}{ No effect on any measure $(30 \mathrm{mg} / \mathrm{kg})$} \\
\hline 8-OH-quinoline & $93.89(64.8-136.0)$ & No effect $(30 \mathrm{mg} / \mathrm{kg})$ & $135.16(108.8-167.9)$ & No effect $(30 \mathrm{mg} / \mathrm{kg})$ \\
\hline
\end{tabular}

$\mathrm{MPE}$, percentage of maximum possible effect in tail flick test; nc, not calculated (out of range tested); RI, ring immobility; RT, change in rectal temperature in ${ }^{\circ} \mathrm{C} ; \mathrm{SA}=$ percentage inhibition of spontaneous activity.

*Data from Wiley et al. (2015). 

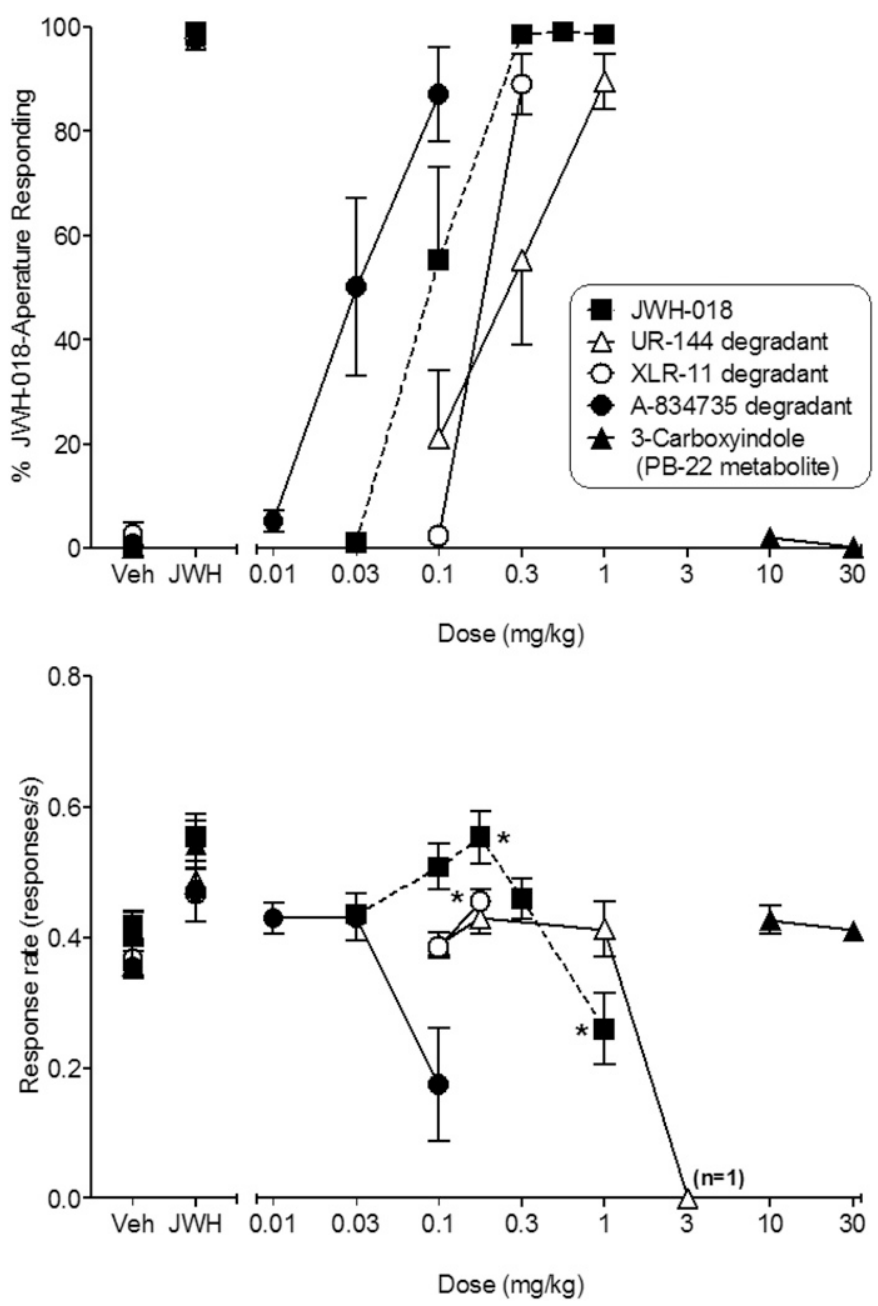

Fig. 5. Effects of JWH-018 (filled squares), UR-144 degradant (unfilled triangles), XLR-11 degradant (unfilled circles), A-834735 degradant (filled circles), and carboxy-PB-22 (filled triangles) on percentage of responses that occurred on the JWH-018-associated aperture (top panel) and response rate (bottom panel). Each point represents the mean ( \pm S.E.M.) of data for seven male C57/Bl6J mice, except for percentage JWH018-associated aperture responding at $3 \mathrm{mg} / \mathrm{kg}$ UR-144 $(n=1), 0.1 \mathrm{mg} / \mathrm{kg}$ A-834735 degradant $(n=4)$, and $1 \mathrm{mg} / \mathrm{kg} \mathrm{JWH}-018(n=6)$. *Significant differences compared with vehicle. Veh, vehicle.

for JWH-018 (Fig. 5, top panel). Potencies for the degradants of UR-144 and XLR-11 were similar, but were 2- to 3-fold less than JWH-018, whereas the potency of the A-834735 degradant was 3-fold greater than JWH-018 (Table 3). In contrast, the 3-carboxyindole metabolite of PB-22 did not substitute at doses of 10 or $30 \mathrm{mg} / \mathrm{kg}$. JWH-018 produced a biphasic effect on

\section{TABLE 3}

Potencies for substitution in JWH-018 discrimination

$\mathrm{ED}_{50}$ values ( $\pm 95 \%$ confidence limits) are expressed in $\mu \mathrm{mol} / \mathrm{kg}$. All compounds were administered i.p. $(\mathrm{n}=7)$. Molecular weight for each compound is provided in parentheses underneath its name.

\begin{tabular}{lcc}
\hline \multicolumn{1}{c}{ Compound } & $\mathrm{CB}_{1} \mathrm{~K}_{\mathrm{i}}$ & $\mathrm{ED}_{50}$ \\
\hline & $n M$ & $\mu m o l / k g$ \\
JWH-018 (341) & $1.22(0.29)^{a}$ & $0.27(0.20-0.36)$ \\
XLR-11 degradant (330) & $5.0(0.6)$ & $0.56(0.51-0.60)$ \\
UR-144 degradant (312) & $11.2(2.5)$ & $0.83(0.51-1.35)$ \\
A-834735 degradant (340) & $4.0(0.6)$ & $0.10(0.07-0.14)$ \\
\hline
\end{tabular}

${ }^{a}$ Data from Brents et al. (2011). response rates (Fig. 5, bottom panel), with increases at $0.3 \mathrm{mg} / \mathrm{kg}$ and decreases at $1 \mathrm{mg} / \mathrm{kg}[\mathrm{F}(5,30)=11.12, P<$ 0.05]. The $0.3-\mathrm{mg} / \mathrm{kg}$ dose of the XLR-11 degradant also significantly increased response rates $[\mathrm{F}(2,12)=7.07, P<$ 0.05]. None of the degradants significantly decreased overall responding at doses that substituted for JWH-018, although a trend was observed for A-834735 (Fig. 5, bottom panel).

The degradants and principal metabolite of PB-22 were evaluated in a separate group of mice trained to discriminate THC from vehicle. In these mice, $30-\mathrm{mg} / \mathrm{kg}$ doses of the 3 -carboxyindole metabolite of PB-22 or $N$-pentylindole and 3 - and $10-\mathrm{mg} / \mathrm{kg}$ doses of 8-OH-quinoline did not substitute for THC $(<20 \%$ responding on the THC-associated aperture; data not shown). Response rates also were not affected by any of these compounds at the doses tested (data not shown).

\section{Discussion}

The chemical diversity of synthetic cannabinoids continues to increase as individuals pursue chemicals for intoxication that can avoid analytical detection and legal prosecution. The evolution of compounds has progressed from alkylindoles with literature or patent precedence to carbazoles and other compounds with little or no pharmacological or toxicological information to support their use as cannabimimetic agents. Indeed, in some instances, the range of substituents being used in synthetic cannabinoid analogs that have been seized and identified by law-enforcement agents has been reported to be relatively unstable (e.g., tetramethylcyclopropyl ring systems, such as that in UR-144, XLR-11, and A-834735) or to include potential carcinogens, such as the aminonaphthalene substituents in $N$-1-naphthalenyl-1-pentyl-1H-indole-3carboxamide (NNEI) and $N$-1-naphthalenyl-1-pentyl-1Hindazole-3-carboxamide (MN-18) (Shevyrin et al., 2013; Uchiyama et al., 2014). The increasing departure from compounds with literature precedent to compounds with no prior pharmacological characterization increases the likelihood of encountering unexpected adverse effects.

This study demonstrates that synthetic cannabinoid analogs not only vary significantly in chemical structure, but can also vary considerably in their thermolytic lability at a temperature $\left(800^{\circ} \mathrm{C}\right)$ approximating temperatures reached during smoking. As a consequence, the chemical exposures occurring during combustion and inhalation are likely to differ significantly from the chemical(s) present in the bulk drug substance. [Lower temperatures $\left(200-250^{\circ} \mathrm{C}\right)$ that accompany use of synthetic cannabinoids in adapted electronic cigarette devices were not investigated here.] For example, the structural constituents of JWH-018 include an indole core, with an $N$-pentyl side chain, and a ketone-linked 1-naphthalene ringsystem substituent. When heated to $800^{\circ} \mathrm{C}$, this compound is volatilized relatively intact, with only a small amount of naphthalene detected as a thermal degradant in the gas/vapor phase. In contrast, UR-144 is susceptible to ring-open degradation, and this occurs readily under the thermolysis conditions used. This ring-opening degradation has also occurred when hand-rolled UR-144 "fortified" marshmallow leaf cigarettes (unfiltered) were smoked using topography conditions for marijuana cigarettes using an automated Borgwaldt KC smoking machine (Borgwaldt-Hauni, Richmond, VA), an experimental paradigm used to simulate commonly used conditions of synthetic cannabinoid abuse. Almost complete 
conversion of UR-144 to the ring-open degradant was observed in the smoke condensate and the cigarette remnant (Thomas et al., 2013). These degradants produced during combustion are transferred into the main smoke stream where they can be inhaled and absorbed by the smoker. Notably, the thermolytic product of UR-144 and its metabolites have been observed in urine obtained from human patients admitted to hospitals with suspected drug intoxication. Indeed, whereas the parent compounds were detected as trace amounts in some urine samples, the hydroxylated/ hydrated metabolite of the UR-144 pyrolysis product was detected in the majority of samples (Grigoryev et al., 2013). These reports are consistent with results of the present study, suggesting that people are being exposed primarily to thermolytic or decomposition products during combustion of herbal material containing UR-144. Although some of these decomposition products have been previously described and shown to possess cannabinoid receptor affinity and/or cannabimimetic activity, others are chemicals of unknown pharmacological or toxicological activity. For example, alkylindole compounds with fluorine at the terminal position of the alkyl chain, such as [1-(5-fluoropentyl)-1H-indol-3-yl]-1naphthalenyl-methanone (AM2201), also undergo dehalogenation (Donohue and Steiner, 2012; Thomas et al., 2015), forming previously synthesized and tested compounds [JWH-018 and 1-naphthalenyl[1-(4-penten-1-yl)-1H-indol3-yl]-methanone (JWH-022)] shown to have high affinity at cannabinoid receptors and to possess cannabimimetic activity (Wiley et al., 1998). Thus, the exposure profiles for various synthetic cannabinoids during smoking may include chemicals that are dramatically different and relatively unpredictable in structure, necessitating empirical testing to fully understand the relationship between exposure and effect.

Results from the in vitro and in vivo testing illustrate how chemicals that are produced thermolytically can have markedly different pharmacological properties compared with the compounds from which they are derived. Some of the thermolytic degradants lost cannabinoid receptor affinity, efficacy, and behavioral activity. For example, degradants of PB-22 ( $N$-pentylindole and 8-OH-quinoline) and its primary metabolite 3-carboxyindole did not bind to $\mathrm{CB}_{1}$ and $\mathrm{CB}_{2}$ receptors, nor did they produce the profile of cannabimimetic effects in mice. The 3-carboxyindole metabolite has also been shown to be inactive at stimulating the $\mathrm{CB}_{1}$ receptor using a novel cannabinoid reporter assay (Cannaert et al., 2016). Other PB-22 metabolites were active, but less potent than $\mathrm{PB}-22$, in this assay. In drug discrimination, the 3-carboxyindole metabolite did not substitute for JWH-018, and the degradants did not substitute for THC. In contrast, the parent compound $\mathrm{PB}-22$ had the greatest affinity for $\mathrm{CB}_{1}$ receptors of all of the indole-derived cannabinoids tested here. Further, it was relatively selective for the $\mathrm{CB}_{1}$ over the $\mathrm{CB}_{2}$ receptor in affinity and activity, stimulating GTP $\gamma$ $\left[{ }^{35} \mathrm{~S}\right]$ binding at the $\mathrm{CB}_{1}$ receptor with high efficacy and failing to stimulate GTP $\gamma\left[{ }^{35} \mathrm{~S}\right]$ binding through the $\mathrm{CB}_{2}$ receptor at all but the highest concentration tested. These findings are in contrast to most of the alkyl indoles where equal or greater receptor affinity and potency in the $\operatorname{GTP} \gamma\left[{ }^{35} \mathrm{~S}\right]$ binding assay is typically seen at the $\mathrm{CB}_{2}$ receptor. However, these results are consistent with data obtained in human $\mathrm{CB}_{1}$ and $\mathrm{CB}_{2}$ receptors using a fluorescence imaging plate reader membrane potential assay, where PB-22 was unique among the alkyl indoles tested, being over 7 -fold more selective for the $\mathrm{CB}_{1}$ receptor (Banister et al., 2015). In vivo, PB-22 was potent in producing the profile of cannabinoid effects in mice, and it substituted fully and potently for THC in rats trained to discriminate THC from vehicle (Gatch and Forster, 2015). Together, these results clearly show that PB-22 is more potent than its degradants and metabolites.

In contrast, the tetramethylcyclopropyl open-ring degradants had higher affinity, increased efficacy, and were more potent in producing cannabimimetic effects in laboratory animals than their parent compounds. Indeed, the ringopen degradants of XLR-11, UR-144, and A-834735 had increased affinity and efficacy, and stimulated GTP $\gamma$ $\left[{ }^{35} \mathrm{~S}\right]$ binding to a greater extent than CP55,940, acting as "super agonists" in $\mathrm{CB}_{1}$-transfected cell lines (Grim et al., 2016; Wiley et al., 2017). This observation is consistent with their derivation from [(3R)-2,3-dihydro-5-methyl-3-(4morpholinylmethyl)pyrrolo[1,2,3-de]-1,4-benzoxazin-6-yl]1-naphthalenyl-methanone, monomethanesulfonate (WIN-55212-2), which has previously been shown to possess maximal efficacy in this signal transduction assay (Griffin et al., 1998). Since THC acts as a partial agonist at the $\mathrm{CB}_{1}$ receptor in the GTP $\gamma$ $\left[{ }^{35} \mathrm{~S}\right]$ assay, the increased efficacy of these synthetic cannabinoids and their thermolytic degradants may lead to rapid intoxication and difficulty in dose titration during consumption, even in seasoned cannabis users, which may account for the increased calls to poison control and emergency room visits after their consumption. Certainly, the in vivo data support the hypothesis that the ring-open degradants are more potent than THC. Although the potencies of XLR-11 and UR-144 for producing cannabimimetic effects in mice and THC-like discriminative stimulus effects in mice and rats (present study; Wiley et al., 2013; Gatch and Forster, 2015) were relatively similar to THC, their degradants exhibited potencies that were severalfold higher. Indeed, the potencies of the ring-open degradants of XLR-11 and UR-144 in the tetrad battery in mice and in drug discrimination were more similar to JWH-018 than they were to THC. Further, the ring-open degradant of A-834735 was more potent than JWH-018 in drug discrimination. In previous studies, JWH-018 has consistently shown greater potencies than THC in several species, including mice (Wiley et al., 2016), rats (Järbe et al., 2011; Wiley et al., 2014), and nonhuman primates (Ginsburg et al., 2012). The present results suggest that the ring-open degradants of the tetramethylcyclopropyl cannabinoids would be similarly greater in these species. These data epitomize the inherent risks involved in the combustion and inhalation of novel chemical entities that can produce exposures to chemicals and degradants, resulting in unanticipated pharmacological effects.

The increasing degree of structural variability in synthetic cannabinoid compounds being used as designer drugs, and their susceptibility to degradation as demonstrated by heating under laboratory conditions, leads to extreme uncertainties as to the amount of parent compound and the types and amounts of degradants reaching the brain and other systems under real-world conditions of synthesis, storage, distribution, and use. As the number of new chemical entities continues to grow, along with new methods of administration, such as "vaping," the threat to public health is likely to increase. 


\section{Acknowledgments}

The authors kindly acknowledge the assistance of Vicki McCall and Dayle Johnson in the preparation of graphics for publication.

\section{Authorship Contributions}

Participated in research design: Thomas, Wiley, Lefever, Grabenauer.

Conducted experiments: Cortes, Patel, Kovach, Cox.

Performed data analysis: Thomas, Wiley.

Wrote or contributed to the writing of the manuscript: Thomas, Wiley, Kevin, Gamage, Marusich, Lefever, Pollard.

\section{References}

Adamowicz P, Zuba D, and Sekuła K (2013) Analysis of UR-144 and its pyrolysis product in blood and their metabolites in urine. Forensic Sci Int 233:320-327.

Auwarter V, Dresen S, Weinmann W, Muller M, Putz M, and Ferreiros N (2009) 'Spice' and other herbal blends: harmless incense or cannabinoid designer drugs? $J$ Mass Spectrom 44:832-837.

Banister SD, Stuart J, Kevin RC, Edington A, Longworth M, Wilkinson SM, Beinat C, Buchanan AS, Hibbs DE, Glass M, et al. (2015) Effects of bioisosteric fluorine in synthetic cannabinoid designer drugs JWH-018, AM-2201, UR-144, XLR-11, PB-22, 5F-PB-22, APICA, and STS-135. ACS Chem Neurosci 6:1546-1559.

Behonick G, Shanks KG, Firchau DJ, Mathur G, Lynch CF, Nashelsky M, Jaskierny DJ, and Meroueh C (2014) Four postmortem case reports with quantitative detection of the synthetic cannabinoid, 5F-PB-22. J Anal Toxicol 38:559-562.

Bell S and Nida C (2015) Pyrolysis of drugs of abuse: a comprehensive review. Drug Test Anal 7:445-456.

Brents LK, Reichard EE, Zimmerman SM, Moran JH, Fantegrossi WE, and Prather PL (2011) Phase I hydroxylated metabolites of the K2 synthetic cannabinoid JWH-018 retain in vitro and in vivo cannabinoid 1 receptor affinity and activity. PLoS One 6:e21917.

Cannaert A, Storme J, Franz F, Auwärter V, and Stove CP (2016) Detection and activity profiling of synthetic cannabinoids and their metabolites with a newly developed bioassay. Anal Chem 88:11476-11485.

Creary X, Hudock F, Keller M, Kerwin JF, Jr, and Dinnocenzo JP (1977) Protolytic and pyrolytic rearrangements of polycyclic methyl cyclopropyl ketones. J Org Chem 42:409-414.

Donohue KM and Steiner RR (2012) JWH-018 and JWH-022 as combustion products of AM2201. Microgram J 9:52-56.

European Monitoring Centre for Drugs and Drug Addiction(2010) Drug profileSynthetic cannabinoids and 'Spice'. http://www.emcdda.europa.eu/publications/ drug-profiles/synthetic-cannabinoids

European Monitoring Centre for Drugs and Drug Addiction(2015) Synthetic cannabinoids in Europe. http://www.emcdda.europa.eu/topics/pods/syntheticcannabinoids

Federal Register (2013) Schedules of controlled substances: temporary placement of three synthetic cannabinoids into Schedule I. Final order. Fed Regist 78: $28735-28739$.

Federal Register (2014) Schedules of controlled substances: temporary placement of four synthetic cannabinoids into Schedule I. Final order. Fed Regist 79:7577-7582.

Federal Register (2015a) Schedules of controlled substances: extension of temporary placement of UR-144, XLR11, and AKB48 in schedule I of the Controlled Substances Act. Final order. Fed Regist 80:27854-27856.

Federal Register (2015b) Schedules of controlled substances: temporary placement of three synthetic cannabinoids into schedule I. Final order. Fed Regist 80 5042-5047.

Federal Register (2016) Schedules of Controlled Substances: Placement of PB-22, 5F-PB-22, AB-FUBINACA and ADB-PINACA into Schedule I. Final rule. Fed Regist 81: 61130-61133.

Gatch MB and Forster MJ (2015) $\Delta$ 9-Tetrahydrocannabinol-like effects of novel synthetic cannabinoids found on the gray market. Behav Pharmacol 26:460-468.

Ginsburg BC, Schulze DR, Hruba L, and McMahon LR (2012) JWH-018 and JWH073: delta-tetrahydrocannabinol-like discriminative stimulus effects in monkeys. $J$ Pharmacol Exp Ther 340:37-45.

Griffin G, Atkinson PJ, Showalter VM, Martin BR, and Abood ME (1998) Evaluation of cannabinoid receptor agonists and antagonists using the guanosine-5'-O-(3[35S]thio)-triphosphate binding assay in rat cerebellar membranes. $J$ Pharmacol Exp Ther 285:553-560.

Grigoryev A, Kavanagh P, Melnik A, Savchuk S, and Simonov A (2013) Gas and liquid chromatography-mass spectrometry detection of the urinary metabolites of UR-144 and its major pyrolysis product. J Anal Toxicol 37:265-276.

Grim TW, Morales AJ, Gonek MM, Wiley JL, Thomas BF, Endres GW, Sim-Selley LJ, Selley DE, Negus SS, and Lichtman AH (2016) Stratification of cannabinoid 1 receptor (CB1) agonist efficacy: Manipulation of CB1 density through use of transgenic mice reveals congruence between in vivo and in vitro assays. $J$ Pharmacol Exp Ther 359:329-339.

Hermanns-Clausen M, Kneisel S, Szabo B, and Auwarter V (2013) Acute toxicity due to the confirmed consumption of synthetic cannabinoids: clinical and laboratory findings. Addiction 108:534-544.

Hoyte CO, Jacob J, Monte AA, Al-Jumaan M, Bronstein AC, and Heard KJ (2012) A characterization of synthetic cannabinoid exposures reported to the National Poison Data System in 2010. Ann Emerg Med 60:435-438.

Järbe TU, Deng H, Vadivel SK, and Makriyannis A (2011) Cannabinergic aminoalkylindoles, including AM678= JWH018 found in 'Spice', examined using drug (Delta9-tetrahydrocannabinol) discrimination for rats. Behav Pharmacol 22:498-507.

Kavanagh P, Grigoryev A, Savchuk S, Mikhura I, and Formanovsky A (2013) UR-144 in products sold via the Internet: identification of related compounds and characterization of pyrolysis products. Drug Test Anal 5:683-692.

Koller VJ, Ferk F, Al-Serori H, Misik M, Nersesyan A, Auwarter V, Grummt T, and Knasmuller S (2015) Genotoxic properties of representatives of alkylindazoles and aminoalkyl-indoles which are consumed as synthetic cannabinoids. Food Chem Toxicol 80:130-136.

Langston JW, Ballard P, Tetrud JW, and Irwin I (1983) Chronic Parkinsonism in humans due to a product of meperidine-analog synthesis. Science 219:979-980.

Lapoint J, James LP, Moran CL, Nelson LS, Hoffman RS, and Moran JH (2011) Severe toxicity following synthetic cannabinoid ingestion. Clin Toxicol (Phila) 49: 760-764.

Law R, Schier J, Martin C, Chang A, and Wolkin A (2015) Notes from the Field: Increase in Reported Adverse Health Effects Related to Synthetic Cannabinoid Use - United States, January-May 2015. MMWR Morb Mortal Wkly Rep 64: 618-619.

Martin BR, Compton DR, Thomas BF, Prescott WR, Little PJ, Razdan RK, Johnson MR, Melvin LS, Mechoulam R, and Ward SJ (1991) Behavioral, biochemical, and molecular modeling evaluations of cannabinoid analogs. Pharmacol Biochem Behav 40:471-478.

Monte AA, Bronstein AC, Cao DJ, Heard KJ, Hoppe JA, Hoyte CO, Iwanicki JL, and Lavonas EJ (2014) An outbreak of exposure to a novel synthetic cannabinoid. $N$ Engl J Med 370:389-390.

Roberts RM and Landolt RG (1965) Thermal rearrangement of cyclopropyl ketones to homoallylic ketones. Relationship to the "abnormal Claisen rearrangement". $3 \mathrm{~J}$ Am Chem Soc 87:2281-2282.

Schwartz MD, Trecki J, Edison LA, Steck AR, Arnold JK, and Gerona RR (2015) A common source outbreak of severe delirium associated with exposure to the novel synthetic cannabinoid ADB-PINACA. J Emerg Med 48:573-580.

Shevyrin V, Melkozerov V, Nevero A, Eltsov O, and Shafran Y (2013) Analytical characterization of some synthetic cannabinoids, derivatives of indole-3-carboxylic acid. Forensic Sci Int 232:1-10.

Thomas BF, Daw RC, Pande PG, Cox AO, Kovach AL, Davis Jr KH, and Grabenauer M (2013) Analysis of smoke condensate from combustion of synthetic cannabinoids in herbal products, in The 23rd Annual Symposium of the International Cannabinoid Research Society; 2013 June 25; Vancouver, British Columbia, Canada. pp P4-24, International Cannabinoid Research Society, Research Triangle Park, North Carolina.

Thomas BF, Wiley JL, and Endres GW (2015) Synthetic cannabinoids are recurring chemical threats. Cayman Currents $\mathbf{2 6 : 1 - 3}$

Thomas S, Bliss S, and Malik M (2012) Suicidal ideation and self-harm following K2 use. J Okla State Med Assoc 105:430-433.

Thornton SL, Wood C, Friesen MW, and Gerona RR (2013) Synthetic cannabinoid use associated with acute kidney injury. Clin Toxicol (Phila) 51:189-190.

Tse R, Kodur S, Squires B, and Collins N (2014) Sudden cardiac death complicating acute myocardial infarction following synthetic cannabinoid use. Int Med J 44: 934-936.

Uchiyama N, Matsuda S, Kawamura M, Shimokawa Y, Kikura-Hanajiri R, Aritake $\mathrm{K}$, Urade Y, and Goda Y (2014) Characterization of four new designer drugs, 5-chloro-NNEI, NNEI indazole analog, alpha-PHPP and alpha-POP, with 11 newly distributed designer drugs in illegal products. Forensic Sci Int 243:1-13.

Wiley JL, Compton DR, Dai D, Lainton JAH, Phillips M, Huffman JW, and Martin BR (1998) Structure-activity relationships of indole- and pyrrole-derived cannabinoids. J Pharmacol Exp Ther 285:995-1004.

Wiley JL, Lefever TW, Marusich JA, Antonazzo KR, Wallgren MT, Cortes RA, Patel PR, Grabenauer M, Moore KN, and Thomas BF (2015) AB-CHMINACA, AB-PINACA, and FUBIMINA: Affinity and potency of novel synthetic cannabinoids in producing $\Delta^{9}$-tetrahydrocannabinol-like effects in mice. J Pharmacol Exp Ther 354:328-339.

Wiley JL, Lefever TW, Marusich JA, and Craft RM (2017) Comparison of the discriminative stimulus and response rate effects of $\Delta^{9}$-tetrahydrocannabinol and synthetic cannabinoids in female and male rats. Drug Alcohol Depend 172:51-59.

Wiley JL, Marusich JA, Lefever TW, and Cortes RA (2014) Cross-substitution of $\Delta^{9}$. tetrahydrocannabinol and JWH-018 in drug discrimination in rats. Pharmacol Biochem Behav 124:123-128.

Wiley JL, Marusich JA, Lefever TW, Grabenauer M, Moore KN, Huffman JW, and Thomas BF (2016) Evaluation of first generation synthetic cannabinoids on binding at non-cannabinoid receptors and in a battery of in vivo assays in mice. Neuropharmacology 110:143-153.

Wiley JL, Marusich JA, Lefever TW, Grabenauer M, Moore KN, and Thomas BF (2013) Cannabinoids in disguise: $\Delta^{9}$-Tetrahydrocannabinol-like effects of tetramethylcyclopropyl ketone indoles. Neuropharmacology 75:145-154.

Winstock AR and Barratt MJ (2013) Synthetic cannabis: A comparison of patterns of use and effect profile with natural cannabis in a large global sample. Drug Alcohol Depend 131:106-111.

Zhang Y, Gilliam A, Maitra R, Damaj MI, Tajuba JM, Seltzman HH, and Thomas BF (2010) Synthesis and biological evaluation of bivalent ligands for the cannabinoid 1 receptor. J Med Chem 53:7048-7060.

Address correspondence to: Dr. Brian F. Thomas, RTI International, 3040 Cornwallis Road, Research Triangle Park, NC 27709-2194., E-mail: bft@ rti.org, (in vitro work) or Dr. Jenny L. Wiley, RTI International, 3040 Cornwallis Road, Research Triangle Park, NC 27709-2194. E-mail: jwiley@rti.org (in vivo work) 